\title{
New Poly(amide-imide) Syntheses XXII. Synthesis and Properties of Poly(amide-imide)s Based on 1,4-Bis(4-trimellitimidophenoxy)-2-t-butylbenzene and Aromatic Diamines
}

\author{
Chin-Ping Yang, ${ }^{\dagger}$ Sheng-Huei HsiaO, and Huei-Wen Yang \\ Department of Chemical Engineering, Tatung Institute of Technology, 40 Chungshan \\ North Rd., Sec. 3, Taipei 104, Taiwan, Republic of China
}

(Received February 19, 1998)

\begin{abstract}
A diimide dicarboxylic acid, 1,4-bis(4-trimellitimidophenoxy)-2-t-butylbenzene (I), was prepared by the condensation of 1,4-bis(4-aminophenoxy)-2-t-butylbenzene (BAP- $t$ BB) and trimellitic anhydride (TMA) in $1: 2$ molar ratio. A series of novel poly(amide-imide)s (PAIs) $\mathbf{I I I}_{\mathrm{a}-1}$ having inherent viscosities of $0.98-1.51 \mathrm{dL}^{-1}$ were prepared by the triphenyl phosphite activated polycondensation from the diimide-diacid $\mathbf{I}$ with various aromatic diamines $\left(\mathbf{I I}_{\mathbf{a}-1}\right)$ in a medium consisting of $N$-methyl-2-pyrrolidone (NMP), pyridine, and calcium chloride. Most of polymers show excellent solubility in amide-type solvents such as NMP and $N, N$-dimethylacetamide (DMAc) and formed tough, transparent, and flexible films by casting from DMAc solution. These films had tensile strengths of $71-106 \mathrm{MPa}$, elongations at break of 5-45\%, and initial moduli of $2.1-2.9 \mathrm{GPa}$. Most PAIs necked during the tensile testing. The glass transition temperatures of these polymers were in the range $228-286^{\circ} \mathrm{C}$ and the $10 \%$ weight loss temperatures were above $475^{\circ} \mathrm{C}$ in air or in nitrogen.

KEY WORDS 1,4-Bis(4-aminophenoxy)-2- $t$-butylbenzene / Trimellitic Anhydride / 1,4-Bis(4-trimellitimidophenoxy)-2-t-butylbenzene / Poly(amide-imide)s /
\end{abstract}

Aromatic polyimides have earned a reputation as high-performance materials based on their excellent thermal stability, chemical resistance, and outstanding mechanical properties. ${ }^{1-4}$ However, poor handling and intractable characteristics have been major problems due to high melting point and insolubility. To extend the utility of such high performance materials, it has been a long-desired goal to synthesize soluble polymers without much sacrifice in their thermomechanical properties. It is well known that the synthesis of poly(amide-imide)s (PAIs) can offer a compromise between excellent thermal stability and processability.

In our previous studies, ${ }^{5-12}$ we have successfully applied the phosphorylation polycondensation technique $^{13-15}$ to prepare PAIs from imide-containing dicarboxylic acids and aromatic diamines. This route provides significant advantages in manufacturing operations compared with conventional methods. Thus, many new series of PAIs could be readily developed by this convenient technique in our laboratory. Polyamides on the basis of diamine 1,4-bis(4-aminophenoxy)-2-t-butylbenzene (BAP- $t$ BB) have been claimed to possess the potential application as gas separation membranes. ${ }^{16} \mathrm{It}$ has been reported that incorporating the residue of BAP- $t$ BB into polyimide backbones led to decreased crystallinity and glass transition temperature. ${ }^{17}$ The present work was undertaken to synthesize and characterize a series of novel aromatic PAIs on the basis of the diimide-diacid derived from BAP- $t \mathrm{BB}$ and trimellitic anhydride. Thus, it is expected that the PAIs prepared from the diimide-diacid would give higher solubility compared to those of the corresponding PAIs without $t$-butyl substituent prepared from our previous study. ${ }^{7}$ These PAIs are also expected to be potential candidates for gas separation membranes because of the presence of pendent bulky $t$-butyl group.

\footnotetext{
† To whom correspondence should be addressed.
}

\section{EXPERIMENTAL}

\section{Materials}

Trimellitic anhydride (TMA) (Wako) was used without previous purification. BAP- $t$ BB $\left(\mathrm{mp} 129-130^{\circ} \mathrm{C}\right)$ was synthesized from $t$-butylhydroquinone and $p$-chloronitrobenzene in the presence of potassium carbonate and subsequent reduction with a $10 \% \mathrm{Pd}-\mathrm{C}$ catalyst and hydrazine hydrate in our previous studies. ${ }^{8-12} p$ Phenylenediamine ( $\left.\mathbf{I I}_{\mathrm{a}}\right)$ (Wako) and $m$-phenylenediamine $\left(\mathbf{I I}_{\mathrm{b}}\right)(\mathrm{TCI})$ were vacuum-distilled, and benzidine $\left(\mathbf{I I}_{\mathrm{c}}\right)$ (TCI) was crystallized prior to use. Other diamines that included 4,4'-diaminobenzanilide $\left(\mathbf{I I}_{\mathrm{d}}\right), 4,4^{\prime}$-oxydianiline $\left(\mathbf{I I}_{\mathrm{e}}\right)$, 4,4'-diaminodiphenyl sulfide $\left(\mathbf{I I}_{\mathrm{f}}\right), 4,4^{\prime}$-diaminodiphenylmethane (II $)$, 1,4-bis(4-aminophenoxy)benzene $\left(\mathbf{I I}_{h}\right), 1,3$-bis(4-aminophenoxy) benzene $\left(\mathbf{I I}_{\mathrm{i}}\right)$, , 2,-bis[4-(4aminophenoxy)phenyl]propane $\left(\mathbf{I}_{\mathbf{k}}\right)$, and 2,2-bis[4-(4aminophenoxy)phenyl] hexafluoropropane ( $\left.\mathbf{I I}_{1}\right)$ were all from TCI and used without any further purification. Bis[4-(4-aminophenoxy)phenyl] ether ( $\left.\mathbf{I I}_{\mathbf{j}}\right)$ (mp 109$110^{\circ} \mathrm{C}$ ) was prepared according to a reported method. ${ }^{18}$ $N, N$-Dimethylacetamide (DMAc; Fluka), $N, N$-dimethylformamide (DMF; Fluka), and pyridine (Wako) were purified by distillation under reduced pressure over calcium hydride and stored over $4 \AA$ molecular sieves. Triphenyl phosphite (TPP; TCI) was purified by vacuum-distillation. Commercially obtained calcium chloride $\left(\mathrm{CaCl}_{2}\right.$; Wako) was dried under vacuum at $180^{\circ} \mathrm{C}$ for $10 \mathrm{~h}$.

\section{Synthesis of 1,4-Bis(4-trimellitidophenoxy)-2-t-butylben- zene (I) \\ A mixture of $6.96 \mathrm{~g}(20 \mathrm{mmol})$ of diamine BAP- $t \mathrm{BB}$ and $7.69 \mathrm{~g}(40 \mathrm{mmol})$ of TMA were heated to dissolve in $50 \mathrm{~mL}$ of dry DMF. Stirring and heating at $40^{\circ} \mathrm{C}$ were continued for $1 \mathrm{~h}$. Then, about $20 \mathrm{~mL}$ of toluene was added, and the mixture was heated with reflux for about $6 \mathrm{~h}$ until about $1.1 \mathrm{~mL}$ of water was distilled off azeo-}


tropically under a Dean-Stark trap. After complete removal of water, the residual toluene was distilled off. After cooling, the precipitated yellowish solid was isolated by filtration, washed several times by hot water, and dried in vacuum to yield $13.6 \mathrm{~g}(98 \%)$ of pure diimide-diacid $\mathbf{I}$; $\mathrm{mp} 338-339^{\circ} \mathrm{C}$.

IR (KBr): $3500-2500$ (carboxyl-OH), 1780 and 1726 (imide $\mathrm{C}=\mathrm{O}$ ), 1092 and $729 \mathrm{~cm}^{-1}$ (imide ring $\mathrm{C}-\mathrm{N}$ ).

Anal. Calcd for $\mathrm{C}_{40} \mathrm{H}_{28} \mathrm{O}_{10} \mathrm{~N}_{2}$ (696.67): C, 68.96\%; H, 4.05\%; N, 4.02\%. Found: C, 68.54\%; H, 4.3\%; N, $3.67 \%$.

${ }^{1} \mathrm{H}$ NMR (dimethyl sulfoxide (DMSO)- $\left.d_{6}\right): \delta(\mathrm{ppm})=$ $8.38-8.42\left(\mathrm{~d}, 2 \mathrm{H}, \mathrm{H}_{\mathrm{b}}\right), 8.28\left(\mathrm{~s}, 2 \mathrm{H}, \mathrm{H}_{\mathrm{a}}\right), 8.04-8.07(\mathrm{~d}$, $\left.2 \mathrm{H}, \mathrm{H}_{\mathrm{c}}\right), 7.45-7.49\left(\mathrm{~d}, 4 \mathrm{H}, \mathrm{H}_{\mathrm{d}}\right), 7.15-7.11(\mathrm{~m}, 5 \mathrm{H}$, $\left.\mathrm{H}_{\mathrm{e}}+\mathrm{H}_{\mathrm{h}}\right), 6.98-6.99\left(\mathrm{~d}, 2 \mathrm{H}, \mathrm{H}_{\mathrm{f}}+\mathrm{H}_{\mathrm{g}}\right), 1.38\left(\mathrm{~s}, 9 \mathrm{H}, \mathrm{H}_{\mathrm{i}}\right)$.

${ }^{13} \mathrm{C}$ NMR (DMSO- $\left.d_{6}\right): \delta(\mathrm{ppm})=166.52,165.96$, $157.47,157.11,151.845,150.68,143.12,136.57,135.57$ $134.99,132.12,129.15,126.58,126.24,123.85,123.46$, $122.64,118.76,118.21,118.09,117.80,34.58,29.83$.

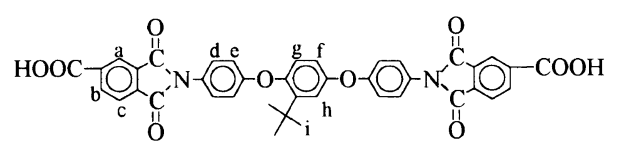

I

\section{Polymerization}

A typical example of polymerization is as follows. A mixture of $0.435 \mathrm{~g}(0.625 \mathrm{mmol})$ of diimide-diacid $\mathbf{I}$, $0.126 \mathrm{~g}(0.625 \mathrm{mmol})$ of diamine $\mathbf{I I}_{\mathrm{d}}, 0.3 \mathrm{~g}$ of $\mathrm{CaCl}_{2}, 4 \mathrm{~mL}$ of NMP, $0.8 \mathrm{~mL}$ of pyridine and $0.4 \mathrm{~mL}$ of TPP was heated with stirring at $100^{\circ} \mathrm{C}$ for $3 \mathrm{~h}$. The polymer solution was too viscous to stir after about $1 \mathrm{~h}$ and was diluted gradually with an additional $3 \mathrm{~mL}$ of $N$-methyl pyrrolidone (NMP) to maintain smooth stirring. The polymer solution obtained was trickled on $100 \mathrm{~mL}$ of stirring methanol giving rise to a stringy precipitate which was washed thoroughly with methanol and hot water, collected by filtration, and dried under vacuum at $100^{\circ} \mathrm{C}$. The yield was $0.55 \mathrm{~g}(98 \%)$. The inherent viscosity of the PAI III $_{\mathrm{d}}$ was $1.51 \mathrm{dL} \mathrm{g}^{-1}$, as measured on $0.5 \mathrm{~g} \mathrm{dL}^{-1}$ in DMAc at $30^{\circ} \mathrm{C}$.

Other PAIs were synthesized in an analogous procedure.

\section{Measurements}

Elemental analyses were run in a Perkin-Elmer Model $2400 \mathrm{C}, \mathrm{H}, \mathrm{N}$, analyzer. ${ }^{1} \mathrm{H}$ and ${ }^{13} \mathrm{C}$ NMR spectra were determined on a JEOL EX-200 FT-NMR spectrometer. IR spectra were recorded on a JASCO FTIR-7000 Fourier-transform Infrared Spectrometer. The inherent viscosities were measured with a Cannon-Fenske viscometer at $30^{\circ} \mathrm{C}$. DSC traces were measured on a Sinku Riko 7000 differential scanning calorimeter coupled to a basic component TA 7000 thermal analyzer at the rate of $10^{\circ} \mathrm{Cmin}^{-1}$ in flowing nitrogen $(30$ $\mathrm{cm}^{3} \mathrm{~min}^{-1}$ ). Thermogravimetry (TG) was conducted with TA Instruments TGA 2050. Experiments were carried out on $10 \pm 2 \mathrm{mg}$ samples heated in flowing nitrogen $\left(50 \mathrm{~cm}^{3} \mathrm{~min}^{-1}\right)$ at a heating rate of $20^{\circ} \mathrm{C} \mathrm{min}^{-1}$. An Instron Universal Tester Model 1130 with a load cell of $5 \mathrm{~kg}$ was used to study the stress-strain behavior of the polymer films. A gauge of $2 \mathrm{~cm}$ and a strain rate of



Scheme 1. Preparation of diimide-diacid.

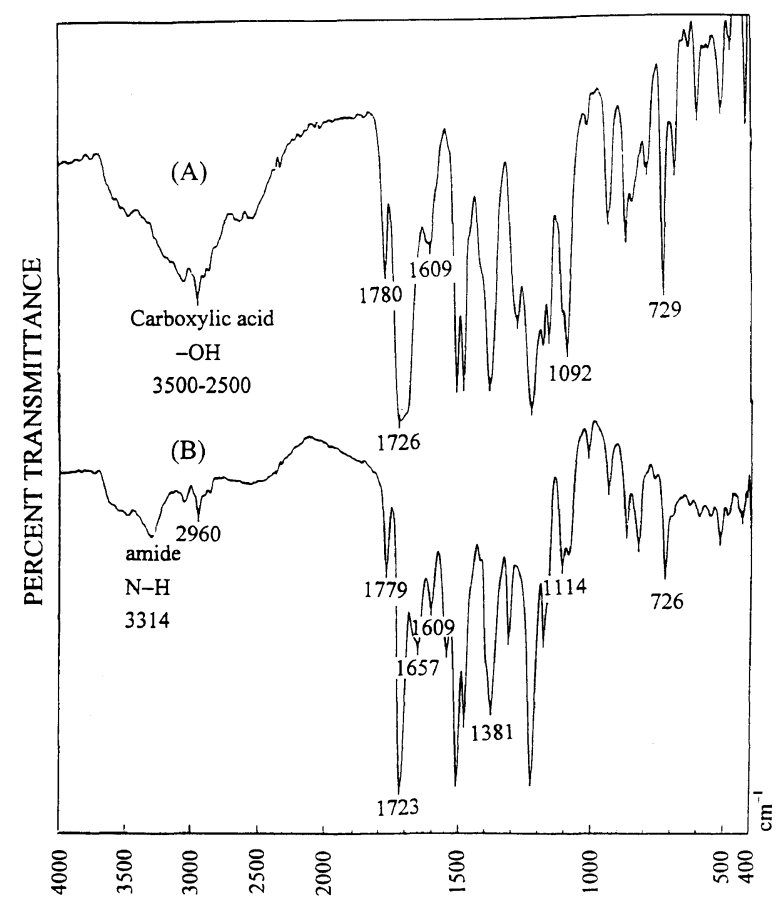

Figure 1. FT-IR spectra of (A) diimide-diacid I and (B) poly(amideimide) III $_{\mathrm{a}}$.

$5 \mathrm{~cm} \min ^{-1}$ were used for this study. Measurements were performed at room temperature with film specimens $(0.5 \mathrm{~cm}$ wide, $6 \mathrm{~cm}$ long, and about $0.5 \mathrm{~mm}$ thick $)$ and an average of at least five individual determinations was used.

\section{RESULTS AND DISCUSSION}

\section{Synthesis}

1,4-Bis(4-trimellitimidophenoxy)-2-t-butylbenzene (I), the diimide-diacid monomer, was prepared via the two-stage procedure that included ring-opening addition of the diamine BAP- $t \mathrm{BB}$ with two equivalent amounts of trimellitic anhydride, followed by cyclodehydration to the diimide-diacid by means of toluene--water azeotropic distillation (Scheme 1). The structure of I was confirmed by elemental analysis and $\mathrm{IR},{ }^{1} \mathrm{H}$, and ${ }^{13} \mathrm{C} \mathrm{NMR}$ spectroscopy. The FT-IR spectrum of diimide-diacid I is reproduced in Figure 1(A). The absorption bands appearing between 2500-3500 (carboxyl -OH), 1780 (imide, asymmetric $\mathrm{C}=\mathrm{O}$ stretching), 1726 (carboxyl $\mathrm{C}=\mathrm{O}$ and symmetric imide $\mathrm{C}=\mathrm{O}$ stretching), 1092 and $729 \mathrm{~cm}^{-1}$ (imide ring deformation) establish the presence of carboxyl group and imide rings in the structure of the monomer synthesized. The ${ }^{13} \mathrm{C}$ NMR spectrum of 


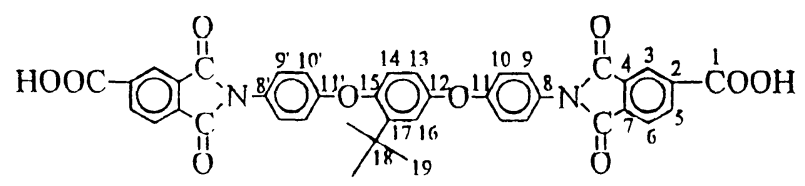

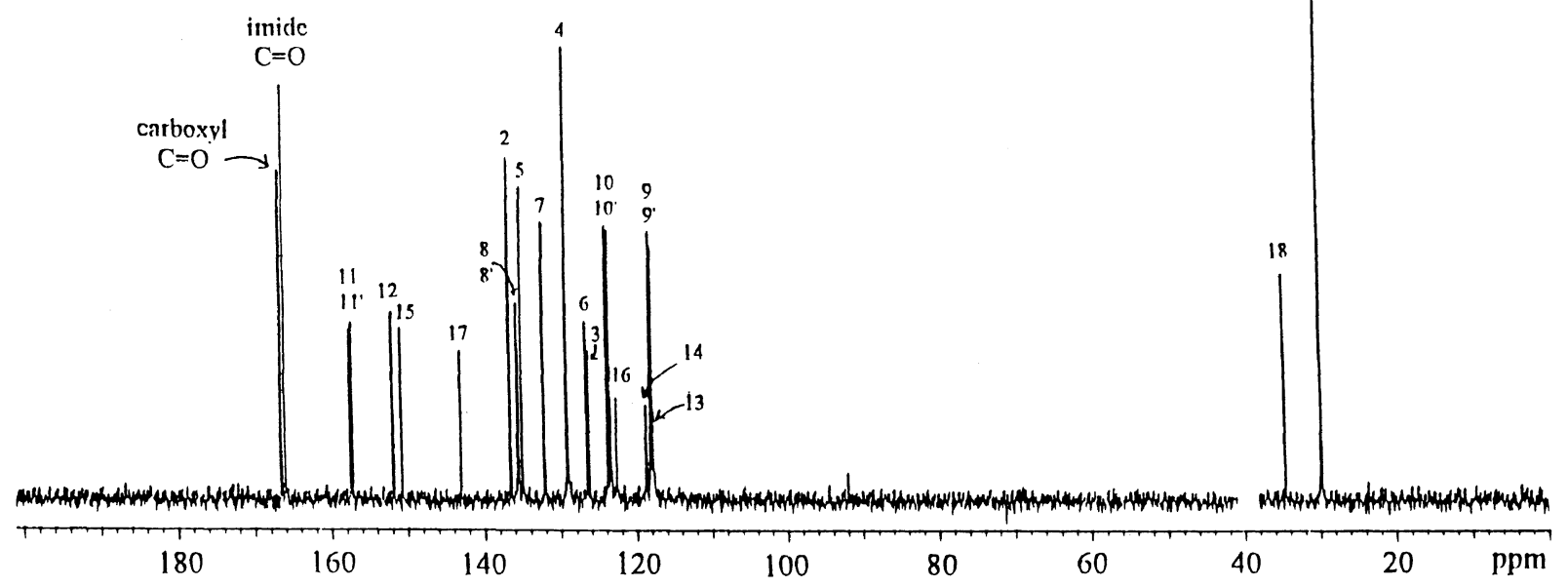

Figure 2. The $50 \mathrm{MHz}{ }^{13} \mathrm{C}$ NMR spectrum of diimide-diacid $\mathbf{I}$ in DMSO- $d_{6}$.



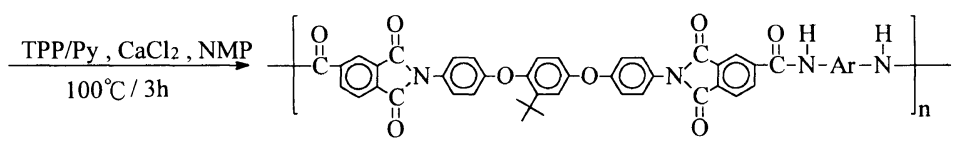

III

Ar:

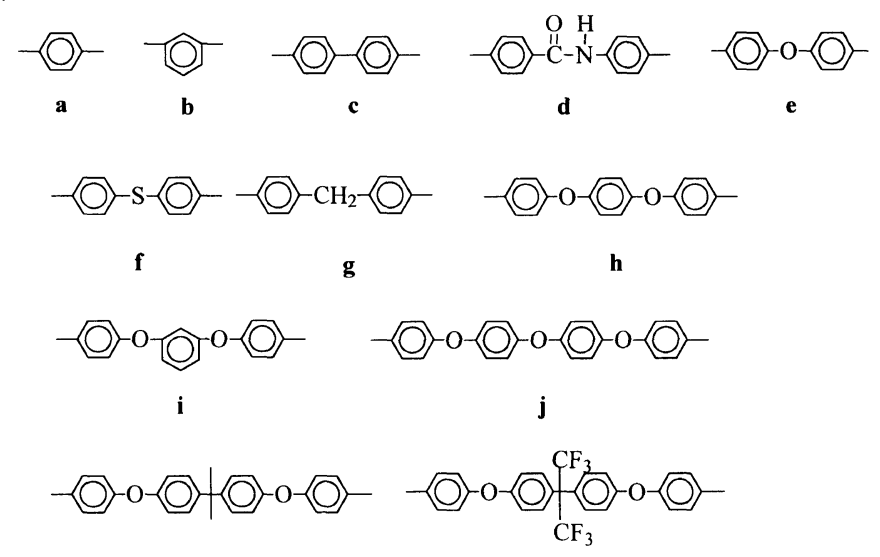

I

Scheme 2. Preparation of poly(amide-imide)s.

diimide-diacid I shown in Figure 2 was in good agreement with the proposed structure.

A series of novel PAIs III $_{a-1}$ were prepared from diimide-diacid $\mathbf{I}$ and various aromatic diamines $\mathbf{I I}_{\mathbf{a}-1}$ by the direct condensation reaction using triphenyl phosphite and pyridine as condensing agent (Scheme 2). Synthesis conditions and inherent viscosities of the PAIs produced are shown in Table I. Under these conditions the reaction solutions were homogeneously transparent throughout the reaction. The solubility of the polymer and the state of stirring affected the inherent viscosity of the resulting PAI significantly. In general, the molecular weight of the polymer obtained from the phosphorylation reaction is highly dependent on the reactant concentration. According to our earlier publications, ${ }^{5-10}$ it was repeatly observed that the higher the concentration of 
C.-P. YANG, S.-H. HsiaO, and H.-W. YANG

Table I. Synthesis of poly(amide-imide)s

\begin{tabular}{|c|c|c|c|c|c|c|c|}
\hline \multirow{3}{*}{$\begin{array}{l}\text { Polymer } \\
\text { code }\end{array}$} & \multirow{3}{*}{$\frac{\begin{array}{c}\text { Amount of } \\
\text { each } \\
\text { monomer }\end{array}}{\text { mmol }}$} & \multicolumn{5}{|c|}{ Amounts of reagents used ${ }^{a}$} & \multirow{3}{*}{$\frac{\eta_{\text {inh }}{ }^{b}}{\mathrm{dLg}^{-1}}$} \\
\hline & & \multirow{2}{*}{$\frac{\text { NMP }}{m L}$} & \multirow{2}{*}{$\begin{array}{c}\begin{array}{c}\text { Additional } \\
\text { NMP }\end{array} \\
\mathrm{mL}\end{array}$} & \multirow{2}{*}{$\frac{\mathrm{CaCl}_{2}}{\mathrm{~g}}$} & \multirow{2}{*}{$\frac{P y}{m L}$} & \multirow{2}{*}{$\frac{\mathrm{TPP}}{\mathrm{mL}}$} & \\
\hline & & & & & & & \\
\hline III $_{\mathrm{a}}$ & 0.830 & 5.0 & & 0.38 & 1.0 & 0.55 & 1.11 \\
\hline IIII $_{\mathrm{b}}$ & 0.740 & 5.0 & & 0.38 & 1.0 & 0.55 & 1.04 \\
\hline III $_{\mathrm{c}}$ & 0.625 & 3.5 & 1.0 & 0.37 & 0.8 & 0.40 & $1.10^{\mathrm{c}}$ \\
\hline $\mathrm{III}_{\mathrm{d}}$ & 0.625 & 4.0 & 3.0 & 0.30 & 0.8 & 0.40 & 1.51 \\
\hline III $_{\mathrm{e}}$ & 0.625 & 3.5 & 1.5 & 0.27 & 0.8 & 0.40 & 1.25 \\
\hline III $_{\mathrm{f}}$ & 1.000 & 5.0 & & 0.37 & 1.2 & 0.60 & 1.02 \\
\hline III $_{\mathrm{g}}$ & 0.625 & 3.5 & & 0.27 & 0.8 & 0.40 & 1.01 \\
\hline III $_{h}^{6}$ & 0.625 & 3.5 & 1.0 & 0.25 & 0.8 & 0.40 & 0.98 \\
\hline IIII $_{i}$ & 0.625 & 3.5 & & 0.27 & 0.8 & 0.40 & 1.27 \\
\hline $\mathbf{I I I}_{\mathbf{j}}$ & 0.625 & 3.5 & 1.0 & 0.27 & 0.8 & 0.40 & 1.35 \\
\hline $\mathrm{III}_{\mathrm{k}}$ & 0.625 & 3.5 & 1.0 & 0.27 & 0.8 & 0.40 & 1.45 \\
\hline IIII $_{1}$ & 0.625 & 3.5 & & 0.27 & 0.8 & 0.40 & 1.03 \\
\hline
\end{tabular}

${ }^{\text {a }}$ Polymerization was carried out at $100^{\circ} \mathrm{C}$. ${ }^{\mathrm{b}}$ Measured at a concentration of $0.5 \mathrm{~g} \mathrm{dL}-1$ in DMAc at $30^{\circ} \mathrm{C}$. ${ }^{\mathrm{c}}$ Measured at a concentration of $0.5 \mathrm{~g} \mathrm{dL}^{-1}$ in $\mathrm{H}_{2} \mathrm{SO}_{4}$ at $30^{\circ} \mathrm{C}$.

monomers, the higher the final inherent viscosity provided that no precipitation, or gelation, of the product from the reaction medium took place. It was anticipated that the bulky pendent $t$-butyl group-containing PAIs III $_{a-1}$ would have increased solubility in organic solvents and a higher monomer concentration could be tolerated during the polymerization. In some cases, higher molecular weights of the polymers could be obtained by using a higher initial reaction concentration and adding an additional amount of NMP to the highly viscous reaction medium before the formation of swollen gel. The series of PAIs III $_{a-1}$ having inherent viscosities of $0.98-1.51 \mathrm{dL} \mathrm{g}^{-1}$ were obtained in quantitative yield. Except for III $_{c}$, all the other PAIs could be solution cast into flexible and noncreasable films. These results indicated the formation of high molecular weights.

The structures of these polymers were confirmed by IR spectroscopy and elemental analysis. A typical IR spectrum for the representative PAI III $_{a}$ is shown in Figure 1(B). The characteristic absorption bands for imide ring appear around $1780,1726 \mathrm{~cm}^{-1}$ (imide $\mathrm{C}=\mathrm{O}$ ), 1092 and $729 \mathrm{~cm}^{-1}$ (imide ring deformation). Bands of amide groups appear at 3314 and $1657 \mathrm{~cm}^{-1}$. The elemental analysis values of these PAIs are listed in Table II. In most cases, the found values of carbon and nitrogen were lower than the calculated ones for the proposed structures, but the hydrogen values were found to be higher. This may be due to the hygroscopic nature of the amide group. The moisture intake for these PAIs were in the range of $1.58-3.83 \%$. The corrected values were in good agreement with the calculated ones after deducting the amount of moisture intake.

\section{Properties of Polymers}

The qualitative solubility of the PAIs is shown in Table III. Most PAIs were soluble in aprotic dipolar solvents such as NMP, DMAc, and DMF, and even in less polar solvents like $m$-cresol, pyridine, tetrahydrofuran (THF). The high solubility of these polymers may be due in part to the introduction of the pendent $t$-butyl group which hinders the close packing of polymer chains. However the PAIs $\mathbf{I I I}_{\mathrm{a}}, \mathbf{I I I}_{\mathbf{c}}$, and $\mathbf{I I I}_{\mathrm{d}}$ derived from rigid diamines such as $p$-phenylenediamine $\left(\mathbf{I I}_{\mathrm{a}}\right)$, benzidine $\left(\mathbf{I I}_{\mathrm{c}}\right)$, and 4,4'-diaminobenzanilide $\left(\mathbf{I}_{d}\right)$ revealed somewhat limited solubility. In general, the pendent group-containing PAIs III showed significantly higher solubility than their homologs based on hydroquinone-derived diimidediacid. ${ }^{7}$ For example, polymer $\mathbf{I V}_{\mathrm{g}}$ condensed from hydroquinone-based diimide-diacid and 4,4'-diaminodiphenylmethane $\left(\mathbf{I I}_{\mathrm{g}}\right)$ was insoluble in all the organic solvents tested and only soluble in concentrated sulfuric acid. This indicates that the incorporation of pendent $t$-butyl group led to a significant increase in solubility.

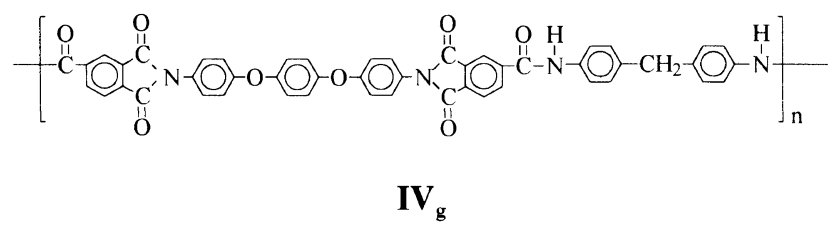

The thermal properties of all the PAIs were evaluated by TG and differential scanning calorimetry (DSC), and the results are summarized in Table IV. DSC measurements were conducted with a heating rate of $10^{\circ} \mathrm{C} \mathrm{min}^{-1}$ in nitrogen. Quenching from an elevated temperature (about $450^{\circ} \mathrm{C}$ ) to room temperature in air gave predominantly amorphous samples so that the glass transition temperatures $\left(T_{\mathrm{g}}\right)$ of almost all the PAIs could be easily observed in the second heating traces of DSC. $T_{\mathrm{g}}$ values of these PAIs were recorded in the range $228-286^{\circ} \mathrm{C}$. This order is correlative to the decreasing order of stiffness and polarity of the polymer backbones. For example, the $T_{\mathrm{g}}$ of the $p$-diphenoxybenzene residuecontaining $\mathbf{I I}_{\mathrm{h}}$ is higher than that of its $m$-isomeric $\mathbf{I I I}$, and the perfluoroisopropylidene-containing III $_{1}$ reveals a higher $T_{\mathrm{g}}$ than its nonfluorinated counterpart $\mathbf{I I}_{\mathrm{k}}$. In general, the $t$-butyl substituent-containing PAIs III showed lower $T_{\mathrm{g}} \mathrm{s}$ in comparison with the corresponding PAIs without $t$-butyl substituent. ${ }^{7}$ Most of the unsubstituted PAIs did not show discernible $T_{\mathrm{g}} \mathrm{s}$ before decomposition, probably due to high crystallinity as evidenced by X-ray diffraction patterns. The decrease in $T_{\mathrm{g}}$ owing to the introduction of the pendent group 
Table II. Elemental analysis of poly(amide-imide)s

\begin{tabular}{|c|c|c|c|c|c|c|}
\hline \multirow{2}{*}{ Polymer } & \multirow{2}{*}{$\frac{\text { Formula }}{M_{w}}$} & & \multicolumn{3}{|c|}{ Elemental analysis $\mathrm{a} / \%$} & \multirow{2}{*}{$\begin{array}{r}\text { Moisture } \\
\text { intake }^{\mathbf{b}} / \%\end{array}$} \\
\hline & & & $\mathrm{C}$ & $\mathrm{H}$ & $\mathrm{N}$ & \\
\hline \multirow[t]{3}{*}{$\mathbf{I I I}_{\mathbf{a}}$} & $\left(\mathrm{C}_{46} \mathrm{H}_{32} \mathrm{O}_{8} \mathrm{~N}_{4}\right)_{n}$ & Calcd & 71.87 & 4.20 & 7.29 & \\
\hline & $(768.78)_{n}$ & Found & 69.27 & 4.46 & 6.96 & 3.65 \\
\hline & & Corrected & 71.89 & 4.30 & 7.22 & \\
\hline \multirow[t]{3}{*}{$\mathbf{I I I}_{\mathrm{b}}$} & $\left(\mathrm{C}_{46} \mathrm{H}_{32} \mathrm{O}_{8} \mathrm{~N}_{4}\right)_{n}$ & Calcd & 71.87 & 4.20 & 7.29 & \\
\hline & $(768.78)_{n}$ & Found & 69.61 & 4.50 & 7.12 & 3.15 \\
\hline & & Corrected & 71.87 & 4.36 & 7.35 & \\
\hline \multirow[t]{3}{*}{ IIII $_{\mathrm{c}}$} & $\left(\mathrm{C}_{52} \mathrm{H}_{36} \mathrm{O}_{8} \mathrm{~N}_{4}\right)_{n}$ & Calcd & 73.93 & 4.27 & 6.64 & \\
\hline & $(844)_{n}$ & Found & 71.75 & 4.52 & 6.47 & 2.87 \\
\hline & & Corrected & 73.87 & 4.39 & 6.67 & \\
\hline \multirow{3}{*}{$\mathbf{I I I}_{\mathrm{d}}$} & $\left(\mathrm{C}_{53} \mathrm{H}_{37} \mathrm{O}_{9} \mathrm{~N}_{5}\right)_{n}$ & Calcd & 71.69 & 4.20 & 7.89 & \\
\hline & $(887.9)_{n}$ & Found & 68.98 & 4.53 & 7.42 & 3.83 \\
\hline & & Corrected & 71.73 & 4.36 & 7.72 & \\
\hline \multirow{3}{*}{ III $_{e}$} & $\left(\mathrm{C}_{52} \mathrm{H}_{36} \mathrm{O}_{9} \mathrm{~N}_{4}\right)_{n}$ & Calcd & 72.22 & 4.21 & 6.51 & \\
\hline & $(860.88)_{n}$ & Found & 69.86 & 4.47 & 6.19 & 1.58 \\
\hline & & Corrected & 70.98 & 4.40 & 6.29 & \\
\hline \multirow[t]{3}{*}{$\mathbf{I I I}_{\mathrm{f}}$} & $\left(\mathrm{C}_{52} \mathrm{H}_{36} \mathrm{O}_{8} \mathrm{~N}_{4} \mathrm{~S}_{1}\right)_{n}$ & Calcd & 71.22 & 4.14 & 6.39 & \\
\hline & $(876.94)_{n}$ & Found & 69.20 & 4.32 & 6.19 & 2.79 \\
\hline & & Corrected & 71.19 & 4.20 & 6.37 & \\
\hline \multirow[t]{3}{*}{ III $_{g}$} & $\left(\mathrm{C}_{53} \mathrm{H}_{38} \mathrm{O}_{8} \mathrm{~N}_{4}\right)_{n}$ & Calcd & 74.12 & 4.46 & 6.52 & \\
\hline & $(858.91)_{n}$ & Found & 72.00 & 4.66 & 6.33 & 2.86 \\
\hline & & Corrected & 74.12 & 4.53 & 6.52 & \\
\hline \multirow[t]{3}{*}{ III $_{\mathrm{h}}$} & $\left(\mathrm{C}_{58} \mathrm{H}_{40} \mathrm{O}_{10} \mathrm{~N}_{4}\right)_{n}$ & Calcd & 73.10 & 4.23 & 5.88 & \\
\hline & $(952.98)_{n}$ & Found & 71.25 & 4.50 & 5.70 & 2.46 \\
\hline & & Corrected & 73.05 & 4.39 & 5.85 & \\
\hline \multirow[t]{3}{*}{$\mathbf{I I I}_{\mathrm{i}}$} & $\left(\mathrm{C}_{58} \mathrm{H}_{40} \mathrm{O}_{10} \mathrm{~N}_{4}\right)_{n}$ & Calcd & 73.10 & 4.23 & 5.88 & \\
\hline & $(952.98)_{n}$ & Found & 70.75 & 4.40 & 5.57 & 3.21 \\
\hline & & Corrected & 73.09 & 4.26 & 5.75 & \\
\hline \multirow[t]{3}{*}{ III $_{\mathbf{j}}$} & $\left(\mathrm{C}_{64} \mathrm{H}_{44} \mathrm{O}_{11} \mathrm{~N}_{4}\right)_{n}$ & Calcd & 73.56 & 4.24 & 5.36 & \\
\hline & $(1045.07)_{n}$ & Found & 72.03 & 4.49 & 5.27 & 2.02 \\
\hline & & Corrected & 73.51 & 4.40 & 5.38 & \\
\hline \multirow[t]{3}{*}{$\mathrm{III}_{\mathrm{k}}$} & $\left(\mathrm{C}_{67} \mathrm{H}_{50} \mathrm{O}_{10} \mathrm{~N}_{4}\right)_{n}$ & Calcd & 75.13 & 4.70 & 5.23 & \\
\hline & $(1071.15)_{n}$ & Found & 73.44 & 4.84 & 5.10 & 2.10 \\
\hline & & Corrected & 75.01 & 4.74 & 5.21 & \\
\hline \multirow[t]{3}{*}{ III $_{1}$} & $\left(\mathrm{C}_{67} \mathrm{H}_{44} \mathrm{O}_{10} \mathrm{~N}_{4} \mathrm{~F}_{6}\right)_{n}$ & Calcd & 68.25 & 3.76 & 4.75 & \\
\hline & $(1179.10)_{n}$ & Found & 67.10 & 4.00 & 4.76 & 1.61 \\
\hline & & Corrected & 68.19 & 3.94 & 4.84 & \\
\hline
\end{tabular}

${ }^{a}$ For $\mathrm{C}$ and $\mathrm{N}$ : Corrected value $=$ found value $\times(100 \%+$ moisture intake $\%)$. For $\mathrm{H}$ : Corrected value $=$ found value $\times(100 \%-$ moisture intake $\%)$. ${ }^{\mathrm{b}}$ Moisture intake $(\%)=\left(\mathrm{W}-\mathrm{W}_{0} / \mathrm{W}_{0}\right) \times 100 \% ; \mathrm{W}=$ weight of polymer sample after standing at room temperature for 3 days, and $\mathrm{W}_{0}=$ weight of polymer sample after dried in vacuum at $100^{\circ} \mathrm{C}$ for $10 \mathrm{~h}$.

Table III. Solubility behavior of poly(amide-imide) $\mathrm{s}^{\mathrm{a}}$

\begin{tabular}{|c|c|c|c|c|c|c|c|c|}
\hline \multirow{2}{*}{ Polymer } & \multicolumn{8}{|c|}{ Solvent ${ }^{\mathrm{b}}$} \\
\hline & NMP & DMAc & DMF & DMSO & $m$-Cresol & $\mathrm{Py}$ & THF & $\mathrm{H}_{2} \mathrm{SO}_{4}$ \\
\hline III $_{a}$ & + & + & $-s$ & + & - & - & - & + \\
\hline III $_{b}$ & + & + & + & + & + & + & + & + \\
\hline III $_{\mathrm{c}}$ & +- & +- & - & - & - & - & - & + \\
\hline III $_{d}$ & + & + & - & + & - & - & - & + \\
\hline $\mathrm{III}_{\mathrm{e}}$ & + & + & + & + & + & + & - & + \\
\hline $\mathrm{III}_{\mathrm{f}}$ & + & + & + & + & + & + & +- & + \\
\hline III $_{\mathrm{g}}$ & + & + & + & + & + & + & + & + \\
\hline $\mathbf{I I I}_{\mathrm{h}}^{\mathrm{o}}$ & + & + & + & + & + & + & - & + \\
\hline $\mathbf{I I I}_{\mathrm{i}}$ & + & + & + & + & + & + & + & + \\
\hline $\mathrm{III}_{\mathrm{j}}$ & + & + & + & + & + & + & + & + \\
\hline III $_{k}$ & + & + & + & + & + & + & + & + \\
\hline IIII $_{1}$ & + & + & + & + & + & + & + & + \\
\hline $\mathbf{I V}_{\mathrm{g}}^{\mathrm{c}}$ & - & - & - & - & - & - & - & + \\
\hline
\end{tabular}

${ }^{\mathrm{a}}+$, soluble; - , insoluble; $-\mathrm{s}$, swelling; +-, partially soluble. ${ }^{\mathrm{b}} \mathrm{NMP}, N$-methyl-2-pyrrolidone; DMAc, $N, N$-dimethylacetamide; DMF, $N, N$-dimethylformamide; DMSO, dimethyl sulfoxide; Py, pyridine; THF, tetrahydrofuran. ${ }^{\mathrm{c}}$ Data from ref 7.

may be attributed to the effect of asymmetry, irregularity, and increased fractional free volume of the polymer chain.

The thermal stability of the PAIs was characterized Polym. J., Vol. 30, No. 9, 1998 by TG analysis conducted at a heating rate of $20^{\circ} \mathrm{C}$ $\min ^{-1}$. The temperatures of $10 \%$ weight loss $\left(T_{10}\right)$ in nitrogen and air atmosphere were determined from original thermograms and also tabulated in Table IV. 


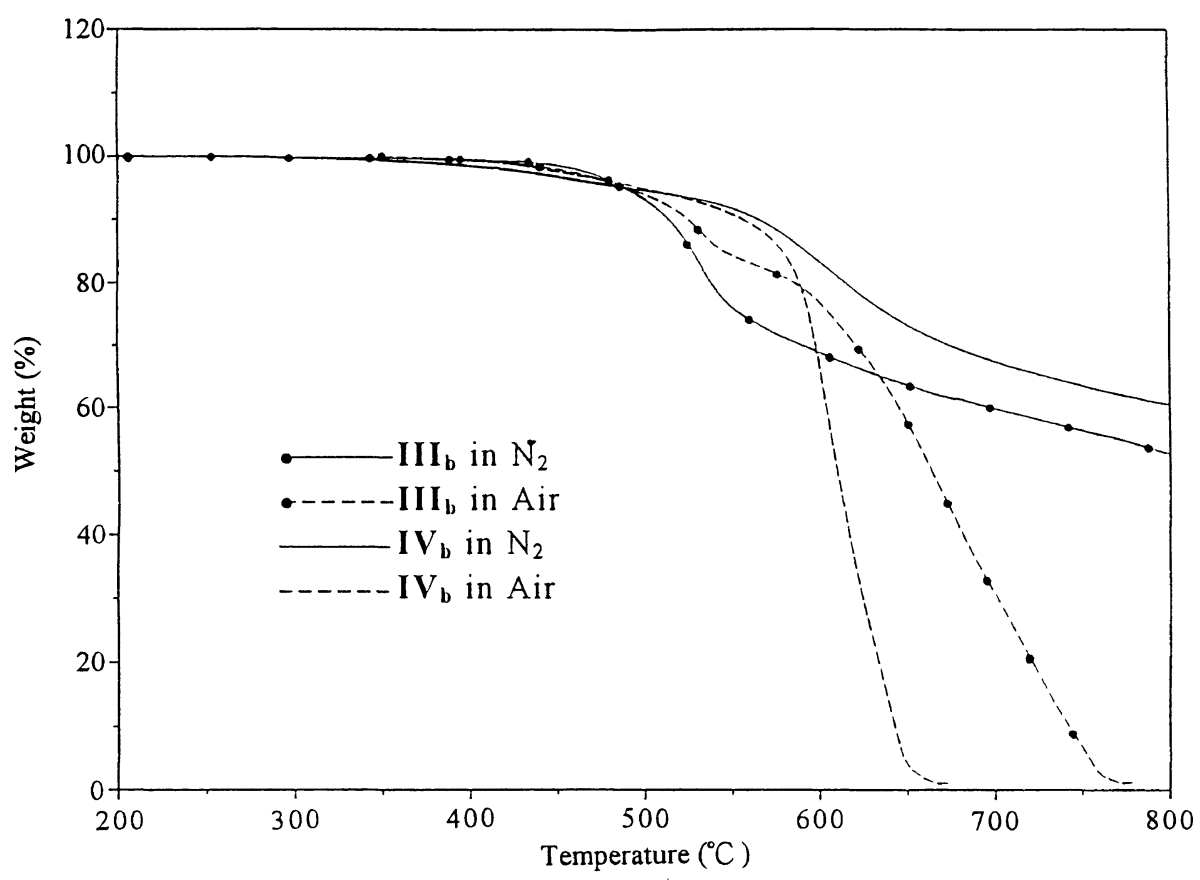

Figure 3. TG curves for PAIs $\mathbf{I I I}_{\mathrm{b}}$ and $\mathbf{I V}_{\mathrm{b}}$ with a heating rate of $20^{\circ} \mathrm{Cmin}^{-1}$.

Table IV. Thermal properties of poly(amide-imide)s

\begin{tabular}{|c|c|c|c|c|}
\hline \multirow{2}{*}{ Polymer } & \multirow{2}{*}{$\frac{T_{\mathrm{g}}^{\mathrm{a}}}{{ }^{\circ} \mathrm{C}}$} & \multicolumn{2}{|c|}{$T_{10}{ }^{\mathrm{b}} /{ }^{\circ} \mathrm{C}$} & \multirow{2}{*}{$\frac{\text { Char yield }^{\mathrm{d}}}{\%}$} \\
\hline & & In $\mathrm{N}_{2}$ & In air & \\
\hline III $_{a}$ & 286 & 521 & 544 & 64 \\
\hline $\mathrm{III}_{\mathrm{b}}$ & 282 & 516 & 525 & 53 \\
\hline III $_{c}$ & $-^{c}$ & 512 & 475 & 49 \\
\hline $\mathbf{I I I}_{\mathrm{d}}$ & 270 & 512 & 510 & 58 \\
\hline III $_{e}$ & 262 & 525 & 530 & 65 \\
\hline III $_{\mathrm{f}}$ & 272 & 490 & 496 & 60 \\
\hline III $_{\mathrm{g}}$ & 256 & 511 & 521 & 68 \\
\hline III $_{\mathrm{h}}^{\mathrm{g}}$ & 266 & 517 & 522 & 59 \\
\hline III $_{\mathrm{i}}$ & 228 & 520 & 522 & 62 \\
\hline $\mathrm{III}_{\mathrm{j}}$ & 244 & 516 & 514 & 55 \\
\hline $\mathrm{III}_{\mathrm{k}}$ & 252 & 510 & 518 & 55 \\
\hline III $_{1}$ & 260 & 521 & 521 & 58 \\
\hline
\end{tabular}

${ }^{a}$ Baseline shift in the second heating DSC traces, with a heating rate of $20^{\circ} \mathrm{C} \mathrm{min}^{-1}$. ${ }^{\mathrm{b}}$ Decomposition temperatures at which $10 \%$ weight loss were recorded by TG at a heating rate $20^{\circ} \mathrm{C} \mathrm{min}^{-1}$. ${ }^{\mathrm{c}}$ Difficult to judge. ${ }^{\mathrm{d}}$ Residual weight $(\%)$ when heated to $800^{\circ} \mathrm{C}$ in nitrogen.

The $T_{10} \mathrm{~s}$ of these PAIs stayed in the range of 490 $521^{\circ} \mathrm{C}$ in nitrogen and $475-544^{\circ} \mathrm{C}$ in air, which is adequately high for an aliphatic group-containing aromatic polymer. In most cases, the $T_{10} \mathrm{~s}$ of these PAIs in air were close to or even higher than those in nitrogen. Figure 3 shows the TG curves of PAI III $_{b}$ and its corresponding PAI $\left(\mathbf{I V}_{\mathrm{b}}\right)$ without the $t$-butyl group. As expected, polymer III $_{b}$ started to lose weight at an earlier temperature than $\mathbf{I} \mathbf{V}_{\mathbf{b}}$ due to the presence of less stable aliphatic $t$-butyl group. PAI III $_{\mathrm{b}}$ did not show significant weight loss up to about $450^{\circ} \mathrm{C}$ in nitrogen and in air, whereas it decomposed rapidly above $500^{\circ} \mathrm{C}$. In nitrogen, the rate of weight loss was slowed down above $550^{\circ} \mathrm{C}$, and about $53 \%$ residual char left at $800^{\circ} \mathrm{C}$. In air, the oxidative degradation continued above $600^{\circ} \mathrm{C}$, and the polymer decomposed completely when heated to about $730^{\circ} \mathrm{C}$. It also can be seen from the TG thermograms of PAI III $_{b}$ that the decomposition rate in air is lower than in nitrogen in the temperature range $500-600^{\circ} \mathrm{C}$. This
Table V. Tensile properties of poly(amide-imide)s films ${ }^{\mathbf{a}}$

\begin{tabular}{|c|c|c|c|c|}
\hline \multirow{2}{*}{ Polymer } & $\begin{array}{l}\text { Strength } \\
\text { at yield }\end{array}$ & $\begin{array}{l}\text { Strength } \\
\text { at break }\end{array}$ & $\begin{array}{c}\text { Elongation } \\
\text { to break }\end{array}$ & $\begin{array}{c}\text { Initial } \\
\text { modulus }\end{array}$ \\
\hline & $\mathrm{MPa}$ & $\mathrm{MPa}$ & $\%$ & $\mathrm{GPa}$ \\
\hline III $_{a}$ & - & 71 & 16 & 2.1 \\
\hline III $_{\mathrm{b}}^{\mathrm{a}}$ & - & 83 & 17 & 2.3 \\
\hline III $_{c}$ & - & - & - & - \\
\hline III $_{d}$ & - & 85 & 5 & 2.7 \\
\hline III $_{e}$ & - & 106 & 13 & 2.9 \\
\hline III $_{\mathrm{f}}$ & - & 93 & 13 & 2.3 \\
\hline III $_{\mathrm{g}}$ & 100 & 101 & 44 & 2.7 \\
\hline III $_{\mathrm{h}}^{\mathrm{g}}$ & 93 & 95 & 45 & 2.7 \\
\hline III $_{\mathrm{i}}$ & 99 & 89 & 11 & 2.6 \\
\hline III $_{\mathrm{j}}$ & 101 & 103 & 31 & 2.7 \\
\hline III $_{k}$ & 95 & 96 & 25 & 2.7 \\
\hline III $_{1}$ & - & 91 & 6 & 2.5 \\
\hline
\end{tabular}

${ }^{\text {a }}$ Films were cast from polymer solutions of DMAc.

may be attributed to the effect of an earlier weight-gained oxidation and to some possible oxidative interchain crosslinking between aliphatic segments of the polymer chain when thermally degraded in air.

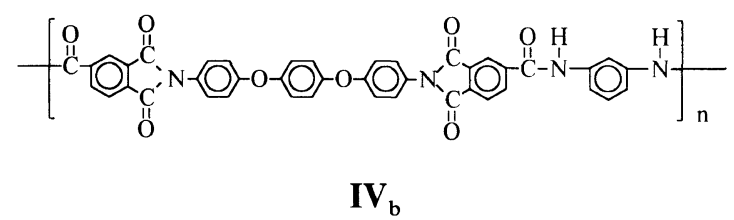

Transparent, flexible and tough films could be cast from the DMAc solutions of the obtained PAIs, except for III $_{c}$ which had poor solubility. Table V summarizes the mechanical properties of the PAIs films. These films had tensile strengths of $71-106 \mathrm{MPa}$, elongations at break of $5-45 \%$, and initial moduli of $2.1-2.9 \mathrm{GPa}$. Some PAIs such as III $_{\mathrm{g}-\mathrm{k}}$ showed clear yield points on their stress-strain curves and had higher elongation-tobreak, indicating high toughness. In comparison with 
PAIs without the pendent group, PAIs III possessed excellent film-formability and superior mechanical properties due to the presence of $t$-butyl substituent.

\section{CONCLUSIONS}

The diimide-diacid 1,4-bis(4-trimellitimidophenoxy)2- $t$-butylbenzene was used as a PAI building block. PAIs having moderate to high molecular weight were successfully prepared by direct polycondensation of the diimide-diacid with various aromatic diamines using triphenyl phosphite and pyridine. The PAIs generally showed good thermal stability and solubility, and their cast films exhibited excellent tensile properties. Thus, the present PAIs are considered as new candidates for processable high-performance polymeric materials. In comparison with the counterparts having no pendent group, this series of PAIs showed an enhanced solubility and film-formability, but slightly lower $T_{\mathrm{g}} \mathrm{s}$ and initial decomposition temperatures due to the attachment of pendent $t$-butyl group.

Acknowledgments. The authors are grateful to the National Science Council of the Republic of China for the support of this work (Grant NSC 87-2216-E-036014).

\section{REFERENCES}

1. D. Wilson, H. D. Stenzenberger, and P. M. Hergenrother, Ed., "Polyimides," Blackie \& Son, Glasgow, 1990.

2. M. J. M. Abadie and B. Sillion, Ed., "Polyimides and Other High-Temperature Polymers," Elsevier, Amsterdam, 1991.

3. C. Feger, M. M. Khojasteh, and M. S. Htoo, Ed., "Advances in Polyimide Science and Technology,” Technomic, Lancaster, 1993.

4. M. K. Ghosh and K. L. Mittal, Ed., "Polyimides: Fundamentals and Applications," Marcel Dekker, New York, N.Y., 1996.

5. C.-P. Yang and S.-H. Hsiao, Makromol. Chem., 190, 2119 (1989).

6. C.-P. Yang and S.-H. Hsiao, J. Polym. Sci., Polym. Chem. Ed., 28, 1149 (1990).

7. C.-P. Yang, S.-H. Hsiao, and W.-L. Chou, J. Polym. Res., 2, 179 (1995).

8. C.-P. Yang and J.-H. Lin, Polym. Int., 38, 335 (1995).

9. C.-P. Yang, S.-H. Hsiao, and J.-H. Lin, J. Polym. Sci., Part A, Polym. Chem. Ed., 30, 1865 (1992).

10. C.-P. Yang and J.-H. Lin, Macromol. Chem. Phys., 196, 3929 (1995).

11. C.-P. Yang, S.-H. Hsiao, and J.-H. Lin, U.S. Pat. 5,268,487 (1993).

12. C.-P. Yang, S.-H. Hsiao, and J.-H. Lin, U.S. Pat. 5,414,070 (1995).

13. N. Yamazaki and F. Higashi, Tetrahedron Lett., 28, 5074 (1972).

14. N. Yamazaki and F. Higashi, Tetrahedron, 30, 1323 (1974).

15. N. Yamazaki, M. Matsumoto, and F. Higashi, J. Polym. Sci., Polym. Chem. Ed., 13, 1373 (1975).

16. O. M. Ekiner, R. A. Hayes, and P. Manos (to Du Pont Co.), U.S. Pat. 5,085,676 (1992)

17. D.-J. Liaw and B.-Y. Liaw, Polym. J., 28, 970 (1996).

18. W. Stackman and A. B. Conciatori, U.S. Pat. 4,064,107 (1977). 